\title{
APPLICATION OF HAZOP AND BOWTIE-XP METHODOLOGIES OF RISK ASSESSMENT ON THE MACONDO OILWELL BLOWOUT
}

\author{
Igbani, Sunday ${ }^{1}$, Orlando, Ketebu ${ }^{2}$, and Yousuo, Digieneni ${ }^{3}$ \\ ${ }^{1-3}$ Department of Chemical and Petroleum Engineering, \\ Niger Delta University, Wilberforce Island, \\ Bayelsa State, Nigeria.
}

\begin{abstract}
The application of HAZOP and BowtieXP methodologies of risk assessment using the Macondo oil well blowout as a case study has been investigated. This study is aimed, to compare and contrast between the HAZOP and BowtieXP methodologies of risk management using the Macondo oil well blowout as a case study. Hence, to accomplish the set aim of the study, the study envisions the Macondo oil well blowout as a scenario, which objectively vector: to evaluate risk management of the Macondo blowout using the Bowtie methodology; to assess risk management of the Macondo blow out using the HAZOP methodology; to prioritize risk assessment methodology within the risk management process; and to show the causes, failed controls, top event, impact, and consequences of the Macondo oil well blowout. To perform the Bowtie Analysis, several steps were followed to ensure an accurate representation of the Bowtie Diagram. Firstly, The TOP EVENT was established. This was the most critical step in Bowtie XP Risk tool. The choice of the TOP EVENT was guided by some questions: What is the risk event? At what point was the safety control lost? At what point did the root causes lead to, and that eventually results in the top event? Next, the preceding events and root causes threats were established. The choices made addressed answered the aforementioned questions relating to the risk controls which failed, the human factors and behaviour which played a role in the elevation of danger and the root causes of the Top Event. This study concludes that the major event of drilling an oil well is a BLOWOUT, which may lead to a catastrophe, and this was identified by both the HAZOP and BowtieXP as STUDY NODES and TOP EVENT, respectively. The consequences of a failed control blowout are Fire, Explosion, Fatal loss of lives, and environmental pollution.
\end{abstract}

Keywords: HAZOP, BowtieXP, Blowout, Macondo, Drilling.

\section{INTRODUCTION}

Since the top event that caused the Santa Barbara Unocal Blowout accident, which occurred in the month of January 1969; safety in the upstream oil and gas industry has become an outstanding concern [1]. On this backdrop, the integration of risk management practices into the oil and gas industry operations has become necessary, to conduct tasks at zero accident and incident or as low as reasonably practicable (ALARP) accident or incident, based on the associated risk on the task. At this point, risk is described as the combination or the likelihood of the occurrence of a harm and the severity of that harm on personnel, object, or the hard or soft intellectuals of an oil and gas organisation [2-3]. Accordingly, Osabutey et. al. [2] described risk assessment as a logical and systematic methodology applied on a proposed task, to establish the context of the task, and to identify the potential risks encapsulated in the task; subsequently, the identified risk on the specific task is analysed or assessed, to control, monitor, and communicate the reviewed control of the risk to the personnel, that would execute the task and other stakeholders. Though, in an earlier study, Zang and Liyun [4] explained that risk assessment is aimed to minimize losses, avoid mitigating losses, and maximize opportunities. This can be contextualized from the root, immediate root, basic causes, and consequences of the disaster of 20th April, 2010 Macondo oilwell blowout in the deepwater horizon, have been reported in many literatures [5-8].

Therefore, the risk of a kick, which may graduate into a blowout is identified as one of the major threats facing the oil and gas well drilling operation. These threats face the safe operation of both the offshore and onshore drilling and production operations. Although, a number of predictable risk assessment approaches and barriers have played important role in identifying major risk in drilling operation, and on other oil and gas facilities [9-10]. Although, most of these barriers have several advantages and disadvantages due to their structural limitations [11].

Consequently, the importance of risk management in a blowout scenario can include, but not limited to the following: risk assessment helps in setting up objectives thereby properly defining the future of an oil firm. if a company defines objectives without taking the risks into consideration, chances are that they will lose direction once any of these risks hit home; with a risk management plan, you can prepare for the unexpected, minimizing risks and extra costs before they eventually happen while also 
saving valuable resources: time, income, assets, people and property can be saved if fewer claims occur; reducing threat of possible litigation; reducing legal liability and increasing the stability of your operations.

In 2006, a HAZOP study was done in the field of Mexilhao, the largest undeveloped gas accumulation as at that time. The study presented the identification and prioritization of potential/probable hazards and the measures for reducing the overall operational risks. With the HAZOP study, blowout contingency plans such as the bubble plume calculations, relief well planning and the dynamic killing design were determined. The HAZOP team was made up of more than twenty (20) professionals from five different companies. The process started with the identification of the hazards or operational problems that can cause adverse consequences or degenerate to such [9]. In another study, following the 1988 disaster on the Piper Alpha Platform which claimed the life of about 167 personnel's, the oil and gas industry was under great pressure to exert more efforts in systemic hazard analysis and risk assessment of their operations. As a result, the Bow-Tie methodology began to appear was used to identify the accident sequences based on the 1988 Piper Alpha accident. This Bowtie analysis framework was extended to include the human decisions and actions, organizational and management factors that influenced the occurrence of these basic events, and their organizational roots. The outcomes of the bowtie analysis allow for the identification of a wide spectrum of possible risk reduction measures, ranging from conventional technical solutions such as addition of redundancies down to organizational improvements such as a change in the maintenance procedures [12].

At this point, it has been observed that both the HAZOP and BowtieXP risk assessment tools have not been used for risk managing drilling operation, simultaneously. Therefore, this study is aimed, to compare and contrast between the HAZOP and BowtieXP methodologies of risk management using the Macondo oilwell blowout as a case study. Hence, to accomplish the set aim of the study, the study envisions the Macondo oilwell blowout as a scenario, which objectively vector: to evaluate risk management of the Macondo blowout using the Bowtie methodology; to assess risk management of the Macondo blow out using the HAZOP methodology; to prioritize risk assessment methodology within the risk management process; and to show the causes, failed controls, top event, impact, and consequences of the Macondo oilwell blowout.

\subsection{METHODOLOGY}

\subsection{Materials/Equipment/software}

The internet's search engines used for this study are as follows: Google Search; Google Scholar; Yahoo Search; Schlumberger Glossaries; OnePetro; PetroWiki. The equipment used are as follows: Bowtie XP application package; a Laptop; A Mobile Hotspot Device; Microsoft Word.

\subsection{Method}

Journals were sourced for using the above stated search engines (Google Search, Google Scholar and Yahoo Search). Direct links to useful resources were obtained from the additional sources of data, which included Schlumberger Glossaries, OnePetro and PetroWiki. A content analysis of related journals was utilized in the preparation of this study. A total of about 130-hours was used for the collection and analysis of the secondary data. To perform the Bowtie Analysis, several steps were followed to ensure an accurate representation of the Bowtie Diagram. Firstly, A TOP EVENT was established. This was the most critical step in Bowtie XP Risk tool. The choice of the TOP EVENT was guided by some questions: What is the risk event? At what point was the safety control lost? At what point did the root causes lead to, and that eventually results in the top event? Next, the preceding events and root causes threats were established. The choices made, addressed and answered the aforementioned questions relating to the risk controls which failed, the human factors and behaviour which played a role in the elevation of danger and the root causes of the Top Event. Following the listing of the threats, appropriate control measures for the respective threats were determined. Suffice to note was that some control measures were found to be peculiar to more than one (1) of the identified threats. Furthermore, the consequences (impact or damages) were established. Recovery methods suitable for each consequence were finally established. The "Guide-Word" HAZOP (hazard operability) was used in the HAZOP analysis of the Macondo Blowout. Critically, focus was placed on precise outcomes of the TOP EVENT (called "study nodes"), one at a time. For each of these study nodes, deviations in the process strictures were examined using the guide words. The guide words ensured that the outcomes were explored in every conceivable way. With this thought, several deviations were established, each of which was well-thought-out carefully, so that their risks (potential causes) and consequences can be identified. Two guide-words were used in this study because only two possible outcomes were possible for each of the presented deviations. Finally, the outcomes of the risk assessment tool (HAZOP and Bowtie XP) are presented next, in section 3.0.

\subsection{RESULTS/DISCUSSION}




\subsection{Results}

The outcomes of the risk assessment tools (HAZOP and Bowtie XP) are presented next on Table 3.1 and Figure 3.1.

TABLE 3.1: HAZOP of the Macondo Blowout of April 20, 2010.

\begin{tabular}{|c|c|c|c|c|c|}
\hline \multirow{2}{*}{ DEVIATION } & \multirow{2}{*}{ CONSEQUENCES } & \multicolumn{2}{|r|}{ GUIDE-WORDS } & \multirow{2}{*}{ CAUSES } & \multirow{2}{*}{ ACTIONS } \\
\hline & & No & Other Than & & \\
\hline $\begin{array}{l}\text { Fault During } \\
\text { Abandonment }\end{array}$ & $\begin{array}{l}\text { Kick leading to a } \\
\text { possible blowout }\end{array}$ & N/A & $\begin{array}{l}\text { Formation } \\
\text { Invasion into wellbore } \\
\text { (Kick) leading to a } \\
\text { blowout }\end{array}$ & $\begin{array}{l}\text { Poor Abandonment } \\
\text { Procedure }\end{array}$ & $\begin{array}{lr}\text { Bottom } & \text { Hole } \\
\text { Cement, Drilling } \\
\text { Fluid } & \text { Column, } \\
\text { Manual Activation of } \\
\text { BOP }\end{array}$ \\
\hline $\begin{array}{ll}\text { Cement } & \text { Seal } \\
\text { Fails } & \end{array}$ & $\begin{array}{l}\text { Kick leading to a } \\
\text { possible blowout }\end{array}$ & N/A & $\begin{array}{l}\text { Formation } \\
\text { Invasion into wellbore } \\
\text { (Kick) leading to a } \\
\text { blowout }\end{array}$ & $\begin{array}{lr}\text { Poor Slurry } & \text { Design, } \\
\text { Improper } & \text { Hole } \\
\text { Cleaning Prior to } \\
\text { Cementing, } & \text { Poor } \\
\text { Cement } & \text { Job, } \\
\text { Insufficient } & \text { Slurry } \\
\text { Volume } & \\
\end{array}$ & $\begin{array}{l}\text { Correction of Cement } \\
\text { Formulation, } \\
\text { Integrity Tests, Use } \\
\text { of Drilling Fluid } \\
\text { Column, Manual } \\
\text { BOP Activation }\end{array}$ \\
\hline $\begin{array}{l}\text { Inadequate } \\
\text { Fluid Column }\end{array}$ & $\begin{array}{l}\text { Kick leading to a } \\
\text { possible blowout }\end{array}$ & N/A & $\begin{array}{l}\text { Formation } \\
\text { Invasion into wellbore } \\
\text { (Kick) leading to a } \\
\text { blowout. }\end{array}$ & 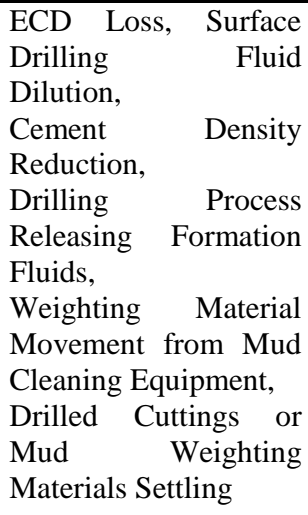 & $\begin{array}{l}\text { Correct Mud Density, } \\
\text { Well } \\
\text { Procedures, Use of } \\
\text { Drilling } \\
\text { Column, } \\
\text { Activation of BOP }\end{array}$ \\
\hline $\begin{array}{lr}\text { BOP Fails } \\
\text { When Needed }\end{array}$ & $\begin{array}{l}\text { Kick leading to a } \\
\text { possible blowout }\end{array}$ & N/A & Blowout. & 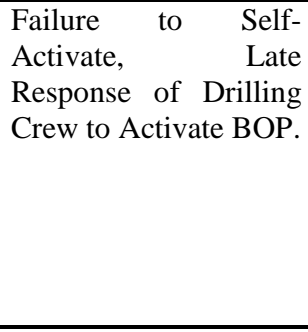 & $\begin{array}{l}\text { Knowing the Design } \\
\text { Limitations Identified } \\
\text { in a Hazard Analysis, } \\
\text { Routine Inspection } \\
\text { and Maintenance, } \\
\text { Drilling Crew } \\
\text { Vigilance and } \\
\text { Response, Manual } \\
\text { Activation of BOP }\end{array}$ \\
\hline
\end{tabular}




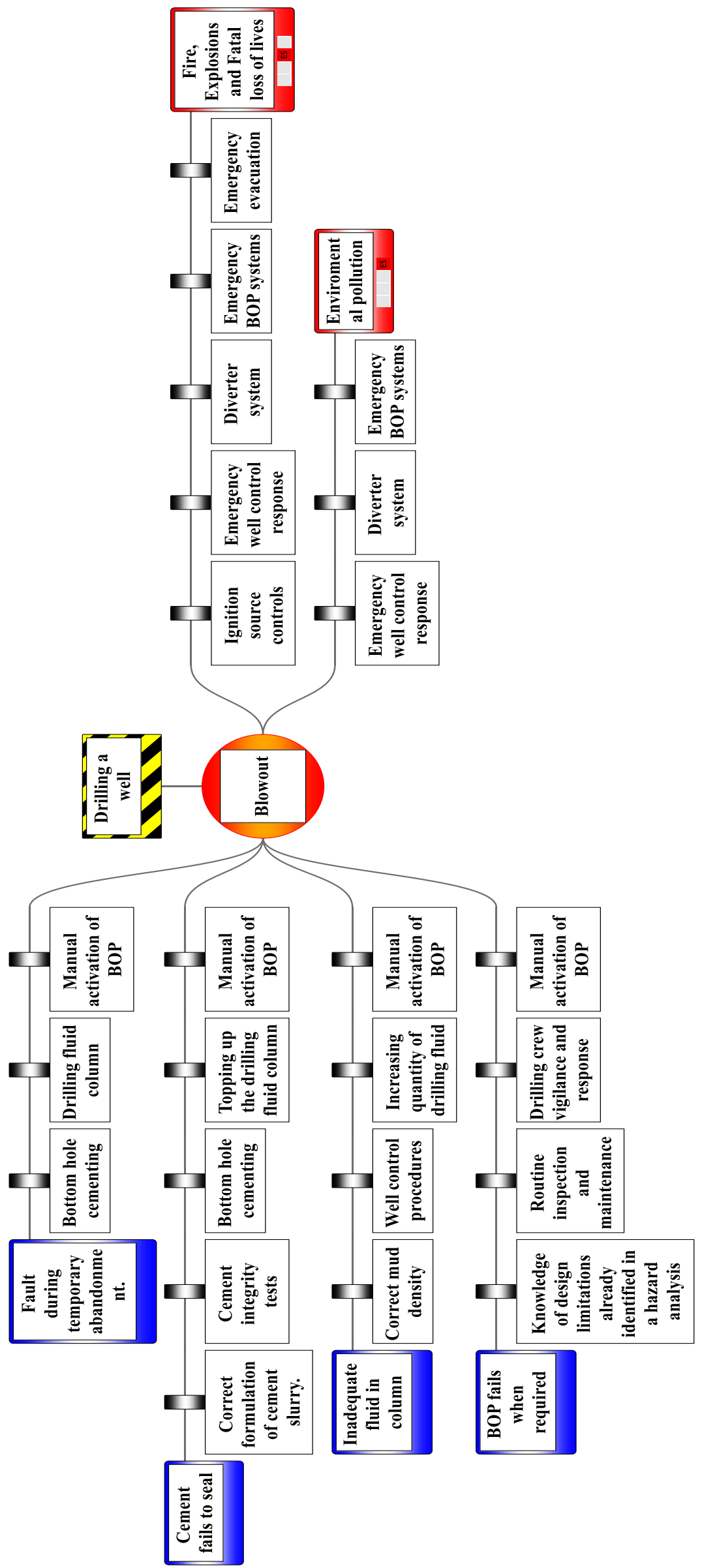

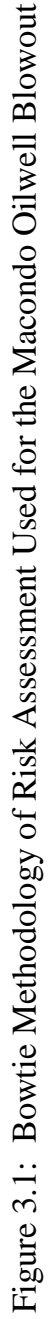




\subsection{Discussion}

Table 3.1 show that, the "Guide-Word" HAZOP was used in the HAZOP analysis of the Macondo Blowout. Focus was placed on precise outcomes of the top event (called 'study nodes'), one at a time. For each of these study nodes, deviations in the process parameters were examined using the 'guide words'. The guide words ensured that the outcomes were explored in every conceivable way. With this thought, several deviations were established, each of which was considered carefully so that their potential causes and consequences was identified. Two guide-words were used in this study because only two possible outcomes were possible for each of the presented deviations. Similarly, Figure 3.1 shows that, the Left Hand Side of the bowtie diagram being the fault tree, highlights the possible threats and risks imposed on the Macondo oil well while drilling operations were being carried out. These threats came in forms of Cement integrity fails, BOP fails and drilling fluid inadequacies. From the bowtie analysis diagram, necessary threat barriers were setup in place which acts as the preventive control measures of the entire process/procedure thus, seeming not to allow the escalation of the known threats in to the top event (Blowout). However, it is imperative to note that the threat barriers of the Macondo oil well failed and as a result several consequences were incurred. The consequences include fire outbreak, explosions, environmental pollution and fatal loss of lives. It becomes necessary to bring in several mitigative control/ recovery methods into play all attempting to realize if the already occurred top event can be limited and salvaged thereby reducing severity and damage to the barest minimum.

None of this is intended to say the Bowties should replace HAZOP, both are complementary tools. There is nothing better than HAZOP for ensuring that process systems are designed fit for purpose. Bowties follow on from this to allow for a through life picture, applicable to all levels of personnel, that can be applied to all risks.

\subsection{CONCLUSION/RECOMMENDATIONS}

\subsection{Conclusion}

This study concludes as follows:

- That the major event of drilling an oilwell is a BLOWOUT, which may lead to a catastrophe, and this was identified by both the HAZOP and BowtieXP as STUDY NODES and TOP EVENT, respectively.

- That both the HAZOP and the BowtieXP risk assessment tools identified that, the causes of a BLOWOUT during drilling may include Poor Abandonment Procedure, Poor Slurry Design, Improper Hole Cleaning Prior to Cementing, Poor Cement Job, Insufficient Slurry Volume, ECD Loss, Surface Drilling Fluid Dilution, Cement Density Reduction, Drilling Process Releasing Formation Fluids, Weighting Material Movement from Mud Cleaning Equipment, Drilled Cuttings or Mud Weighting Materials Settling, Failure to Self-Activate, Late Response of Drilling Crew to Activate BOP.

- That both the HAZOP and the BowtieXP risk assessment tools show that the reviewed controls may deviate during drilling operation, this may include possible fault during abandonment, poor formulation of cement and mud slurries, cement seal failure, inadequate application of cement hydrostatic pressure in the oilwell column, and BOP failure during the kick.

- That both the HAZOP and the BowtieXP risk assessment tools show, that all the barriers or controllers may fail to guide the Formation Fluid Invasion into the wellbore (Kick) leading to a Blowout.

- The consequences of a failed control blowout is Fire, Explosion, Fatal loss of lives, and environmental pollution.

\subsection{Recommendation}

When conducting a Bowtie Analysis, the procedures to arrive at the final analytical diagram are very crucial, as the flow of the graphical representation starts from the top event after which the possible threats that lead the top event is analyzed alongside their preventive control measures thus, leading to the determination of the consequences after the event barriers fail it ends with possible recovery measures that is meant to mitigate the severity of the consequences. Furthermore, it is imperative to note that this research does not intended to show that Bowtie methodology should replace HAZOP. BowtieXP are complementary tools. There is nothing better than HAZOP for ensuring that process systems are designed fit for purpose. Bowties follow on from this to allow for a through life picture, applicable to all levels of personnel, that can be applied to all risks. For which ever case of risk assessment, the Bowtie methodology and the HAZOP Analysis can be used to present valuable information on the threats, consequences and actions that would help mitigate the impacts. However so, the HAZOP is best utilized for futuristic risk assessment while the Bowtie is more useful in the risk assessment of already occurred accidents. 


\section{REFERENCES}

1. ETHW (2015) First-Hand: History of Operational Safety Awareness in the US Gulf of Mexico 1964 to 2014: A personal

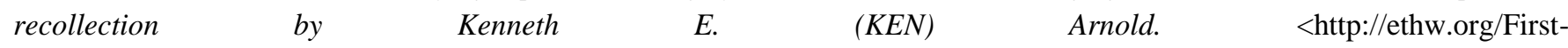
Hand:History_of_Operational_Safety_Awareness_in_the_US_Gulf_of_Mexico_1964_to_2014:_A_personal_recollection_by_ Kenneth_E._(KEN)_Arnold> [13 March 2019].

2. Osabutey, D., Obro-Adibo, G., Agbodohu, W. and Kumi, P. (2013) 'Analysis of Risk Management Practices in the Oil and Gas Industry in Ghana. Case Study of Tema Oil Refinery (Tor)’ European Journal of Business and Management 5(29), 67- 79.

3. ANAO (2018) ANAO Risk Management Framework 2017-2018 [online] available from <https://www.anao.gov.au/work/corporate/anao-risk-management-framework-2016-17> [13 March 2018].

4. Zhang, Y and Liyun, X. (2011) 'Research on Risk Management of Petroleum Operations' Energy Procedia 5(3), $2330-2334$.

5. Mullins, J., (2010) 'the Eight failures that caused the Gulf oil Spill'. News Scientist. Available [Online] https://www.newscientist.com/article/dn19425-the-eight-failures-that-caused-the -gulf-oil-spill/.html [29January 2018].

6. Macondo Prospect, (2010) Gulf of Mexico, USA. Available [online] www.offshore-technology.com/project/macondoprospect/ [28 January 2018].

7. National Commission on the BP Deepwater Horizon Oil Spill and Offshore Drilling (2011). Deep Water The Gulf Oil Disaster and the Future of Offshore Drilling. http://www.oilspillcommission.gov/sites/default/files/documents/DEEPWATER_ReporttothePresident_FINAL.pdf [28 January 2018].

8. Pallardy, R. (2018) 'Deepwater Horizon oil spill of 2010’. Environmental Disaster, Gulf of Mexico. Available [online] <https://www.britannica.com/event/Deepwater-Horizon-oil-spill-of-2010\#> [29 January 2018].

9. Lage, C.V.M, Jacinto, M.C., Martins, S.B., Vanni, S., Otto, L.A. and Moreieas, RF. (2006) 'Blowout Contingency and RiskReduction for High-Rate Subsea Gas Wells in Mexilhao'. Journal of Petroleum Technology.

10. Cholarisk (2019) Practical Application of Bowtie Analysis [online] available from <http://www.cholarisk.com/services/process-safety/qra-hazop/hazard-operability-study-hazop/> [14 March 2019].

11. Khan, F. Abimbola, M. and Hashemi, S.J. (2018) 'Blowout Risk in Drilling and Production'. Encyclopedia of Maritime and Offshore Engineering 3(4), 45-63.

12. Pate-Cornell, M.E. (1993) 'Risk Analysis and Risk Management for Offshore Platforms: Lessons from the Piper Alpha Disaster'. Journal of Offshore Mechanics and Arctic Engineering 3(3), 115. 